\title{
Acute Abdomen in a Patient with a History of Pulmonary Tuberculosis and Endoscopic Retrograde Cholangio-Pancreatography Due to Common Bile Duct Stones
}

\author{
Jamshid Vafaeimanesh ${ }^{1,2, *}$, Rohollah Tghavi ${ }^{3}$, Saeed Madani ${ }^{3}$
}

1. Gastroenterologist, Clinical Research Development Center, Qom University of Medical Sciences, Qom, Iran

2. Qom Gastroenterology and Hepatology Disease Research Center, Qom University of Medical Sciences, Qom, Iran

3. Surgeon, Clinical Research Development Center, Qom University of Medical Sciences, Qom, Iran

* Corresponding Author:

Jamshid Vafaeimanesh, MD

Clinical Research Development Center, Qom University of Medical Sciences, Qom, Iran Telefax: + 982536122949

Email: jvafaeemanesh@yahoo.com

Received: 19 Mar. 2020

Accepted: 04 Jun. 2020
Please cite this paper as:

Vafaeimanesh J, Taghavi R, madani S. Acute Abdomen in a Patient with a History of Pulmonary Tuberculosis and Endoscopic Retrograde Cholangio-Pancreatography Due to Common Bile Duct Stones. Middle East J Dig Dis 2020;12:211-213. doi: 10.34172/mejdd.2020.184.

A 65-year-old woman was admitted with a chief complaint of fever and abdominal pain. The patient had severe abdominal pain with abdominal guarding, and a fever of $38.5^{\circ} \mathrm{C}$. The patient had diarrhea, abdominal pain, and fever for 2 days before the presentation. Her medical history was significant for pulmonary tuberculosis about 45 days earlier. She had also undergone endoscopic retrograde cholangiopancreatography (ERCP) a month earlier because of choledocholithiasis, and a $10-\mathrm{cm}$ biliary stent was inserted for her. The patient also had a history of two abdominal surgeries many years ago but could not remember the reasons. The evaluation of vital signs in the emergency room showed a temperature of $38.5^{\circ} \mathrm{C}$, pulse rate $=98$ beats per minute (bpm), respiratory rate $=17$ breaths per minute, and blood pressure $=125 / 86 \mathrm{mmHg}$. An abdominal examination revealed a distended, tender abdomen. The rest of the physical examination was unremarkable. Laboratory data showed hemoglobin $=10.7$ $\mathrm{g} / \mathrm{dL}$, white blood cell $\left(\mathrm{WBC}\right.$ ) count $=18300 \mathrm{~mm}^{3}$ (with $89 \%$ predominant neutrophils), platelet count $=450.000 \mathrm{~mm}^{3}$, sodium $=136 \mathrm{mmol} / \mathrm{L}$, potassium $=4.2 \mathrm{mmol} / \mathrm{L}$, blood urea nitrogen $=28 \mathrm{mg} / \mathrm{dL}$, and creatinine $=1.92 \mathrm{mg} /$ dL. The patient underwent abdominal computed tomography (figure 1) with showed evidence of peritonitis.
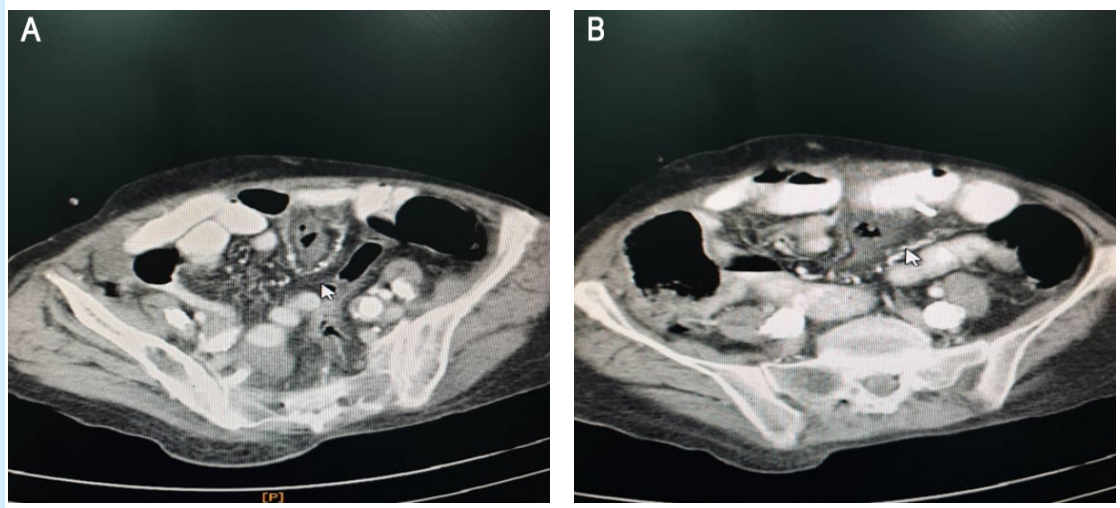

Fig.1: Evidence of peritonitis in computed tomography 

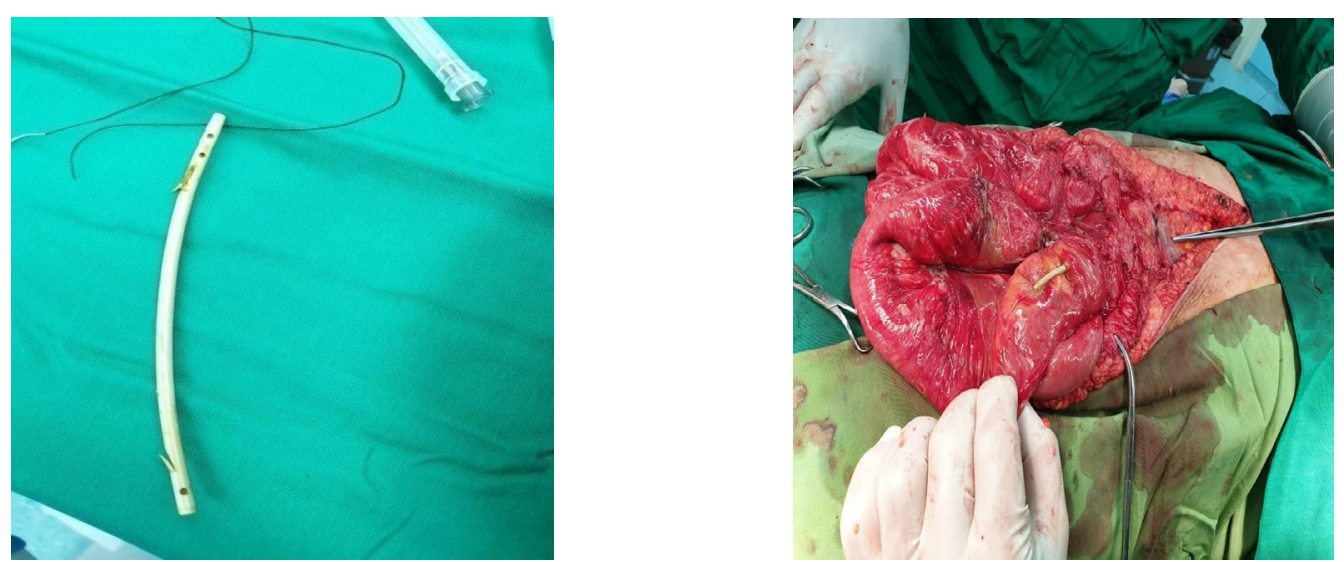

Fig.2: Perforated bowel due to biliary stent, $100 \mathrm{~cm}$ after ligament Tritz

What is your diagnosis?

\section{Answer:}

Peritonitis due to rupture of the small intestine following the distal migration of biliary stents

\section{CONCLUSION}

Endoscopic biliary stenting is a treatment for the management of biliary obstruction secondary to malignant or benign diseases. ${ }^{1}$ The most frequent indication is the decompression of the biliary tract obstructed usually by lithiasis or tumors. They are also indicated in biliary fistulas, prevention of pancreatitis after ERCP, and hemorrhage after sphincterotomy or papillary dilation. ERCP is the procedure for its placement. ${ }^{2}$ The prosthesis can be made of plastic with a half-life of 3-5 months, or of metals with a half-life of 8 months, but the use of metallic ones is limited due to its high cost over plastic ones. ${ }^{3}$ There are complications associated with the placement of the stent with an incidence ranging from $8 \%$ to $10 \%,{ }^{4,5}$ which include cholangitis, cholecystitis, duodenal perforation, bleeding, pancreatitis, fracture of the prosthesis, proximal or distal migration, and occlusion of the stent. 6,7 The migration of the endoprosthesis can be proximal or distal and is associated with certain factors such as the type of malignant or benign pathology, diameter, length, and duration, among others. ${ }^{8}, 9$ Stent extraction is usually performed by ERCP with various techniques such as the use of a balloon, Dormia basket, or Sohendra retractor. ${ }^{10}$ There are few reports of extraction in which open surgery was used.

In cases that the stent stays for a long time, stent migration can occur and, in rare cases, can cause serious complications. Sometimes the diagnosis can be difficult because of the absence of typical symptoms.And sometimes, it leads to intestinal perforation and peritonitis. ${ }^{11}$

Less than $1 \%$ of migrated biliary stents cause bowel perforation. ${ }^{12}$

In the case presented here, the stent entered the small intestine after migration, and because of the adhesion of the intestine following the previous abdominal operations, the intestine was punctured, and the patient developed infectious peritonitis. In a few similar case reports, perforation was often reported in the proximal ligament Tritz, and there are rare cases of distal ligament Tritz puncture, similar to the patient presented by us. ${ }^{13}$ Most notably, most cases occur in patients with intestinal problems such as diverticulitis or those with intestinal adhesions due to previous abdominal surgery.

Our patient underwent a laparotomy, and it was found that the biliary stent caused the rupture of the small intestine and caused peritonitis (Figure 2). The patient was discharged with a good general condition after treatment.

One of the rare complications of biliary stents is peritonitis, which is more likely in patients with bowel problems or abdominal adhesions. Therefore, in such patients, a smaller size biliary stent should be applied more carefully, and it might be removed sooner.

\section{ACKNOWLEDGMENTS}

We hereby thank dear professors and colleagues of the Clinical Research Development Unit of Shahid Beheshti Hospital, who helped the researchers. 


\section{ETHICAL APPROVAL}

There is nothing to be declared. (Informed consent was taken from the patient).

\section{CONFLICT OF INTEREST}

The author declares no conflict of interest related to this work.

\section{Funding}

Our research had no funding.

\section{REFERENCES}

1. Camacho Jaimes ES, Roman Sanchez JS, Benitez Márquez HR. Proximal Migration of Biliary Stent: Case Report. EC Gastroenterol Dig Sys 2019;6:155-62.

2. Somogyi L, Chuttani R,Croffie J,DiSario J,Liu J,Mishkin DS, et al. "Biliary and pancreatic stents". GastrointestEndosc 2006;63:910-9. doi: 10.1016/j.gie.2006.01.013.

3. Isayama H, Kawabe T, Nakailow Y, Tsujino T, Sasahira N, Yamamoto N, et al. Cholecystitis After Metallic Stent Placement in Patients With Malignant Distal Biliary Obstruction. ClinGastroenterolHepatol 2006;4:1148 -53. doi: 10.1016/j.cgh.2006.06.004.

4. Blake AM, Monga N, Dunn EM. Biliary stent causing colovaginal fistula: case report. JSLS 2004;8:73-5.

5. Wurbs D. The development of biliary drainage and stenting. Endoscopy 1998;30:202-6. doi: 10.1055/s-20071001440.

6. Huibregtse K,Katon RM, Coene PP, Tytgat GNJ. Endoscopic palliative treatment in pancreatic cancer. Gastrointest Endosc 1986;32:334-8. doi: 10.1016/s0016-5107(86)71878-6.

7. Baty V, Denis B, Bigard MA, Gaucher P. Sigmoid diverticular perforation relating to the migration of a polyethylene endoprosthesis. Endoscopy 1996;28:781. doi: 10.1055/s-2007-1005606.

8. Johanson JF, Schmalz MJ, Geenen JE. Incidence and risk factors for biliary and pancreatic stent migration. Gastrointest Endosc 1992;38:341-6. doi: 10.1016/s0016-5107(92)70429-5.

9. Nakamura T,Hirai R, Kitagawa M, Takehira Y, Yamada M, Tamakoshi K, et al. Treatment of common bile duct obstruction by pancreatic cancer using various stents: single-center experience. Cardiovasc Intervent Radiol 2002;25:373-80. doi:10.1007/s00270-002-0426-2.

10. Soehendra N, Maydeo A, Eckmann B, Brückner M, Nam $\mathrm{VC}$, Grimm H. A new technique for replacing an obstructed biliary endoprosthesis. Endoscopy 1990;22:271-2.doi: 10.1055/s-2007-1012868.

11. Siaperas P, Ioannidis A, Skarpas A, Angelopoulos A, Drikos I,Karanikas I. A rare cause for Hartmann's procedure due to biliary stent migration: A case report. Int J Surg Case Rep 2017;31:83-5. doi:10.1016/j.ijscr.2017.01.016

12. SarangaBharathi R, Rao P, Ghosh K. Iatrogenic duodenal perforations caused by endoscopic biliary stenting and stent migration: an update. Endoscopy 2006;38:1271-4. doi: $10.1055 / \mathrm{s}-2006-944960$.

13. Akimboye F, Lloyd T, Hobson S, Garcea G. Migration of endoscopic biliary stent and small bowel perforation within an incisional hernia. Surg Laparosc Endosc Percutan Tech 2006;16:39-40. doi: 10.1097/01.sle.0000202198.74569.5a. 